\title{
Lack of deleterious effect on bone mineral density of long-term thyroxine suppressive therapy for differentiated thyroid carcinoma
}

\author{
J L Reverter, S Holgado ${ }^{1}, N$ Alonso, I Salinas, M L Granada ${ }^{2}$ and A Sanmartí
}

Department of Endocrinology and Nutrition, Germans Trias i Pujol Hospital, Carretera de Canyet s/n. 08916, Badalona,

Barcelona, Spain

${ }^{1}$ Department of Rheumatology, Germans Trias i Pujol Hospital, Badalona, Barcelona, Spain

${ }^{2}$ Hormone Laboratory, Germans Trias i Pujol Hospital, Badalona, Barcelona, Spain

(Requests for offprints should be addressed to J L Reverter; Email: jreverter@comb.es)

\begin{abstract}
The effect of subclinical hyperthyroidism on bone mineral density is controversial and could be significant in patients with differentiated thyroid carcinoma who receive suppressive doses of levothyroxine (LT4). To ascertain whether prolonged treatment with LT4 to suppress thyrotropin had a deleterious effect on bone mineral density and/or calcium metabolism in patients thyroidectomized for differentiated thyroid cancer we have performed a cross-sectional study in a group of 88 women (mean \pm SD age: $51 \pm 12$ years) treated with LT4 after near-total thyroidectomy and in a control group of 88 healthy women ( $51 \pm 11$ years) matched for body mass index and menopausal status. We determined calcium metabolism parameters, bone turnover marker $\mathrm{N}$-telopeptide and bone mass density by dual-energy X-ray absorptiometry. No differences were found between patients and controls in calcium metabolism parameters or $\mathrm{N}$-telopeptide except for PTH, which was significantly increased in controls. No differences were found between groups in bone mineral density in femoral neck $\left(0.971 \pm 0.148 \mathrm{gr} / \mathrm{cm}^{2}\right.$ vs $0.956 \pm 0.130 \mathrm{gr} / \mathrm{cm}^{2}$ in patients and controls respectively, $P=0.5$ ). In lumbar spine, bone mineral density values were lower in controls than in patients $\left(1.058 \pm 0.329 \mathrm{gr} / \mathrm{cm}^{2}\right.$ vs $1.155 \pm 0.224 \mathrm{gr} / \mathrm{cm}^{2}$ respectively, $\left.P<0.05\right)$. When premenopausal $(n=44)$ and postmenopausal $(n=44)$ patients were compared with their respective controls, bone mineral density was similar both in femoral neck and lumbar spine. The proportion of women with normal bone mass density, osteopenia and osteoporosis in patient and control groups was similar in pre- and postmenopausal women. In conclusion, long-term suppressive LT4 treatment does not appear to affect skeletal integrity in women with differentiated thyroid carcinoma.
\end{abstract}

Endocrine-Related Cancer (2005) 12 973-981

\section{Introduction}

Osteoporosis is a limiting condition that affects almost $50 \%$ of US women over the age of 50 and the number is expected to rise concomitantly with life expectancy, with an increase from 32 to 69 million persons affected between 1999 and 2050 (Cooper et al. 1992). Furthermore, the number of femoral neck fractures could reach 8.2 million by that date (Gullberg et al. 1997). On the other hand, carcinoma of the thyroid, a less common site of malignancy (accounting for only $0.85 \%$ and $2.5 \%$ of new cancer cases in men and women respectively) is the most rapidly increasing tumour in women and the second most rapidly increasing in the general US population (Jemal et al. 2003). After thyroidectomy and iodine 131 therapy for thyroid remnant ablation, and since most differentiated thyroid carcinomas (follicular and papillary) contain functional thyrotropin (TSH) receptors, adjunct therapy with levothyroxine (LT4) to inhibit this stimulating hormone is effective for reducing tumour recurrence rates (Thyroid Carcinoma Task Force 2001). Thus, owing to the favourable prognosis of differentiated thyroid carcinoma, patients could live 
longer and receive suppressive LT4 treatment for many years (Gilliland et al. 1997). It is therefore important to understand the effect of supraphysiological LT4 treatment on bones (Greenspan \& Greenspan 1999). The relationship between hyperthyroidism and accelerated bone turnover has been well defined since it was first described in 1891 (Von Recklinhausen 1891), and hyperthyroidism appears to affect the predominantly cortical bone in the hip and forearm more than the trabecular bone in the spine (Ross 1994). Nevertheless, the effects of subclinical hyperthyroidism (undetectable TSH levels and total triiodothyronine (TT3) and/or free thyroxine (FT4) in normal range) on bone mineral density (BMD) are less well defined (Toft 2001). Despite publication in the last decade of several studies (Franklyn et al. 1992, Kung et al. 1993, Giannini et al. 1994, Marcocci et al. 1994, McDermott et al. 1995, Muller et al. 1995, Rosen et al. 1998) and meta-analyses on this topic (Faber \& Galloe 1994, Uzzan et al. 1996), evidence that subclinical hyperthyroidism affects skeletal integrity and is therefore a risk factor for osteoporosis, is inconclusive (Greenspan \& Greenspan 1999, Toft 2001, Quan et al. 2002, Murphy \& Williams 2004). The meta-analyses and systematic reviews reported either a decrease in bone mineral density during prolonged subclinical hyperthyroidism, mainly in postmenopausal women, or no changes (Faber \& Galloe 1994, Uzzan et al. 1996, Greenspan \& Greenspan 1999, Lau et al. 2001, Toft 2001, Quan et al. 2002, Murphy \& Williams 2004). Among premenopausal women, the effect does not appear to be significant (Marcocci et al. 1994). Furthermore, individual studies reported both accelerated BMD loss (Kung et al. 1993, McDermott et al. 1995), increased risk of hip fractures (Quan et al. 2002) and no effect (Franklyn et al. 1992, Giannini et al. 1994, Marcocci et al. 1994, Muller et al. 1995, Rosen et al. 1998) in a similar number of reports. Thus, the quality of evidence on the strength of the association between serum TSH and BMD reported in the American Medical Association guidelines for diagnosis and management of subclinical thyroid disease was negative, or only fair in postmenopausal women with a history of overt hyperthyroidism (Surks et al. 2004). The heterogeneity of selected patients, different levels of TSH suppression and measurement techniques for BMD determination could explain this disparity in results (McDermott et al. 1995, Toft 2001, Murphy \& Williams 2004). A study of skeletal integrity in a homogeneous cohort of women under long-term treatment with LT4 for differentiated thyroid carcinoma and sustained TSH suppression is presented.

\section{Methods}

\section{Participants}

This was a cross/sectional study of a group of Caucasian women recruited from the outpatient clinic of the Endocrinology and Nutrition Department of our hospital. Strict selection criteria were applied to minimize the heterogeneity of the sample: (1) age 18 years or older, (2) hypothyroidism due to a near-total thyroidectomy and ablative radioiodine treatment for differentiated thyroid carcinoma at least 3 years before entry to the study, (3) treatment with LT4 at suppressive doses of TSH for more than 3 years prior to entry, (4) full TSH suppression defined by levels under $0.05 \mu \mathrm{IU} /$ $\mathrm{ml}$ in all of the determinations during previous followup with a visit frequency of 2 to $3 /$ year, (5) normal TT3 levels in all determinations during previous follow-up with a visit frequency of 2 to $3 /$ year, (6) absence of recurrent or metastatic disease (all patients had persistently undetectable thyroglobulin and negative radioisotope scans). Patients with previous or current treatment with calcium, hormonal replacement therapy, thiazide diuretics, corticosteroids, bisphosphonates, raloxifene, tamoxifen, vitamin D or other drugs which could interfere with bone metabolism, prolonged immobilization, recent bone fracture, inflammatory osteoarticular disease, diabetes mellitus, serum creatinine levels $>1.3 \mathrm{mg} / \mathrm{dl}$, increased alkaline phosphatase or severe analytical alterations were excluded.

A group of healthy female volunteers, members of hospital staff and first degree relatives of patients, with similar age, body mass index (BMI) (weight in $\mathrm{kg}$ / height $\mathrm{m}^{2}$ ) and menstrual status served as controls. These controls received no remuneration and had never have been treated with LT4.

Patients and controls completed a questionnaire on menstrual history, previous contraceptives, calcium intake, physical activity, smoking habit, coffee and alcohol consumption. Daily calcium intake was estimated on the basis of dairy product intake and graded as deficient or sufficient if under or over $1000 \mathrm{mg} / 24 \mathrm{~h}$. Physical activity was defined as mild (sedentary, minimal activity at home), moderate (habitual exercise at work, walking, stairs) and vigorous (intense or sport activity more than three times per week). In our usual clinical practice we do not recommend vitamin D supplements because sunlight exposure is high in our country.

\section{Analytical and hormone determinations}

In all cases, BMI was registered and a blood sample obtained by venopuncture in an antecubital vein 
without occlusion after an overnight fast. Haematological and biochemical parameters including calcium, inorganic phosphate and alkaline phosphatase were determined in patients and controls by a multichannel standard autoanalyzer. Intact parathormone (PTH) and TSH were determined by chemiluminiscent enzyme-labeled immunomeric assay (Immulite 2000 DPC, Los Angeles CA, USA. Reference range: $12-65 \mathrm{pg} / \mathrm{ml}$ and $0.3-5.5 \mu \mathrm{IU} / \mathrm{ml}$ respectively. Sensitivity of TSH bioassay: $0.004 \mu \mathrm{IU} / \mathrm{ml}), 1-25$ dihydroxyvitamin $\mathrm{D}(1-25(\mathrm{OH}) 2$ vit $\mathrm{D})$ was determined by chemiluminiscence (Dia-Sorin, Stillwater, MN, USA. Reference range: $18-78 \mathrm{pg} / \mathrm{ml}$ ) and 25 hydroxyvitamin D $(25(\mathrm{OH})$ vit $\mathrm{D})$ by radioimmunoassay (Dia-Sorin. Reference range: $18-80 \mathrm{ng} / \mathrm{ml})$. FT4 was determined by a competitive analog chemiluminiscent ELISA (Immulite 2000 DPC. Reference range: $0.8-1.9 \mathrm{ng} / \mathrm{dl}$ ) and TT3 by competitive chemiluminiscent ELISA (Immulite 2000 DPC. Reference range: $0.7-1.7 \mathrm{ng} / \mathrm{ml}$ ). Levels of urinary calcium excretion were determined in a $24-\mathrm{h}$ urine sample and cross-linked $\mathrm{N}$-telopeptide of type I collagen (NTX) 6 levels in second micturition urine sample (uNTX Osteomarck; Ostex International, Inc., Seattle, WA, USA. Reference range: 5-65 nm BCE $/ \mathrm{mM}$ creatinine).

\section{Bone mineral density measurements}

In patients and controls, BMD was measured in the lumbar spine (L2-L4) and proximal femur (femoral neck, total proximal femur) by dual-energy X-ray absorptiometry (DEXA) (Lunar Prodigy, Lunar Corp, Madison, WI, USA). Precision of the system was $0.5 \%$. The equipment was automatically calibrated daily using phantoms following the manufacturer's recommendations. In all cases, BMD values were expressed as g calcium $/ \mathrm{cm}^{2}$, T-score (standard deviation (SD) compared with a healthy Spanish population aged 20 and 40), and Z-score (SD compared with a population adjusted for age, weight and ethnic origin). According to the WHO criteria (Kanis et al. 1994), a T-score $<-2.5 \mathrm{SD}$ was defined as osteoporosis, between -2.5 and $-1.0 \mathrm{SD}$ as osteopenia and $>-1.0$ as normal.

\section{Statistics}

Comparison between subgroups of patients and controls was made by Student's $t$-test, proportions by chi-square test and correlations between BMD and other variables by Pearson's correlation analysis using the SPSS package (SPSS Inc., Chicago, Illinois, USA). In all cases, significance was considered if $P<0.05$. The study had at least $90 \%$ statistical power to detect differences in comparisons between LT4 treated patients and no treated controls. For categorical variables the estimated sample size required to detect a difference of $20 \%$ in the percentage and with a two-sided alpha error of 0.05 and a beta error of 0.1 was 79 subjects per group. For continuous variables the estimated sample size required to detect a difference of 0.5 times the SD (standardized difference) with a two-sided alpha-error of 0.05 and a beta-error of 0.1 was 85 subjects per group.

\section{Results}

Of the 217 eligible patients with differentiated thyroid carcinoma followed in our department, 47 were men and were excluded. Of the remaining 170 women, and according to selection criteria, 91 were recruited, of whom, 88 completed the study (mean \pm SD age: $51 \pm 12$ years, BMI $\left.27.9 \pm 4.6 \mathrm{~kg} / \mathrm{m}^{2}\right)$. Eighty-eight women were selected as controls $(51 \pm 11$ years, BMI $27.0 \pm 4.2 \mathrm{~kg} / \mathrm{m}^{2}$ ) and all completed the study.

\section{Overall group}

In a first analysis, the 176 women included in the complete group of patients $(n=88)$ and controls $(n=88)$ were studied. Mean duration of LT4 treatment was $12 \pm 5$ years and mean LT4 dose to achieve effective TSH suppression was $195 \pm 43 \mu \mathrm{g} / 24 \mathrm{~h}(2.7 \mu \mathrm{g} /$ $\mathrm{kg} / 24 \mathrm{~h}$ ). No differences were found between patients and controls in anthropometric data, physical activity, unhealthy habits or contraceptive therapy. Appropriate dietary calcium intake did not differ in patients and controls (46 vs $47 \%$ respectively). Remarkably, nearly half of the women did not achieve the recommended daily intake of $1000 \mathrm{mg}$ of calcium. As expected, TSH levels were significantly lower $(0.03 \pm 0.03$ vs $1.93 \pm 1.1 \mu \mathrm{IU} / \mathrm{ml}, \quad P<0.01)$ and FT4 higher $(1.9 \pm 0.4$ vs $1.3 \pm 0.1 \mathrm{ng} / \mathrm{dl}, P<0.01)$ in the LT4-treated group compared with controls, and TT3 levels were similar $(1.2 \pm 0.2$ vs $1.3 \pm 0.3 \mathrm{ng} /$ $\mathrm{ml}, P=0.2)$. Serum calcium $(9.3 \pm 0.5$ vs $9.4 \pm 0.4 \mathrm{mg} /$ dl, $P=0.1)$, serum phosphate $(3.5 \pm 0.7$ vs $3.4 \pm 0.7$ $\mathrm{mg} / \mathrm{dl}, \quad P=0.3), \quad 1-25(\mathrm{OH}) 2 \quad$ vitD $\quad(37.5 \pm 26.6 \quad$ vs $38.2 \pm 19.3 \mathrm{pg} / \mathrm{ml}, P=0.8), 25(\mathrm{OH})$ vitD $(39.9 \pm 19.3$ vs $34.0 \pm 20.8 \mathrm{ng} / \mathrm{ml}, P=0.1)$ and urinary calcium excretion $\quad(171.0 \pm 90.6$ vs $150.6 \pm 75.8 \mathrm{mg} / 24 \mathrm{~h}$, $P=0.2$ ) showed no differences between patients and controls. PTH levels were significantly higher in the control group vs the patient group $(48.7 \pm 18.0$ vs $39.6 \pm 17.8 \mathrm{pg} / \mathrm{ml}$ respectively, $P<0.01)$. Increased PTH levels with respect to normal range were observed in $4.8 \%$ of patients and $13.6 \%$ of controls. However in 
all these cases calcium, phosphate, $1-25(\mathrm{OH}) 2$ vitamin D and $25(\mathrm{OH})$ vitamin $\mathrm{D}$ were within normal range and no hyperfunctioning parathyroid adenomas were detected in subsequent evaluations. The bone resorption marker NTX was similar between patients and controls $(41.3 \pm 22.0$ vs $41.0 \pm 22.6 \mathrm{~nm} \mathrm{BCE} / \mathrm{mM}$ creatinine, $P=0.9$, respectively). With respect to bone mineral density, DEXA results were similar in patients and controls in predominantly cortical bone. Thus, BMD was $0.971 \pm 0.148 \mathrm{~g} / \mathrm{cm}^{2}$ in patients vs $0.956 \pm 0.130 \mathrm{~g}$ / $\mathrm{cm}^{2}$ in controls $(P=0.5)$ in femoral neck. However, BMD values in trabecular bone (in lumbar spine) were significantly decreased in controls compared with patients $\left(1.058 \pm 0.329 \mathrm{~g} / \mathrm{cm}^{2}\right.$ vs $1.155 \pm 0.224 \mathrm{~g} / \mathrm{cm}^{2}$ respectively, $P<0.05)$. T-score and $\mathrm{Z}$-score values in both groups are shown in Fig. 1. The proportion of women with normal bone density and criteria of osteopenia and osteoporosis according to T-score and WHO criteria (Kanis et al. 1994) did not significantly differ between patient and control groups either in femoral neck or lumbar bone. Furthermore, more normal femoral DEXA T-scores and lumbar T-scores and Z-scores were observed, though not statistically significant, in patients than in controls.

\section{Premenopausal women}

In order to assess whether oestrogen status could protect against possible bone loss, premenopausal women ( $n=44$, age $39 \pm 9$ years) were analyzed separately and compared with their respective controls (Table 1). Except for TSH, FT4 and PTH, neither biochemical and calcium metabolism parameters nor $\mathrm{BMD}$, expressed as calcium per area unit, differed between patients and controls (Table 2). In these premenopausal women, femoral neck BMD values were $1.032 \pm 0.124$ vs $1.017 \pm 0.125 \mathrm{~g} / \mathrm{cm}^{2} \quad(P=0.6)$ and in lumbar spine $1.229 \pm 0.167$ vs $1.223 \pm 0.155 \mathrm{~g} /$ $\mathrm{cm}^{2}(P=0.9)$ in patients and controls respectively. The bone resorption marker, NTX, was normal in all subjects, with no significant differences between groups. Compared T-score and Z-score results in predominantly cortical and trabecular bone in premenopausal patients and controls are shown in Fig. 1. The proportion of normal and osteopenic subjects was comparable in all measured bones.

\section{Postmenopausal women}

As shown in Tables 1 and 2, in the postmenopausal subgroup of patients ( $n=44$, age $58 \pm 9$ years), anthropometric data, calcium, phosphate, urinary calcium excretion, 1-25 $(\mathrm{OH}) 2$ vitamin $\mathrm{D}, 25(\mathrm{OH})$ vitamin $\mathrm{D}$ and NTX did not differ between patients and controls.
PTH levels, as observed in premenopausal women, were higher in controls, but parathyroid dysfunction was ruled out. BMD in femoral neck, was $0.921 \pm 0.148 \mathrm{~g} / \mathrm{cm}^{2}$ in controls and $0.927 \pm 0.124 \mathrm{~g} / \mathrm{cm}^{2}$ in patients $(P=0.8)$ and in lumbar spine $0.978 \pm 0.355 \mathrm{~g} / \mathrm{cm}^{2}$ in controls and $1.094 \pm 0.248 \mathrm{~g} / \mathrm{cm}^{2}$ in patients $(P=0.09)$. The values of $\mathrm{T}$-score and Z-score were similar in patients and controls and the proportion of normal and osteopenic subjects based on T-scores did not significantly differ (Fig. 1) and, as in the overall group, a higher, but not significant, proportion of patients with normal skeletal integrity was detected than in controls, particularly in femoral T-score and lumbar $\mathrm{T}$ and $\mathrm{Z}$-scores.

\section{Correlation analysis}

In correlation analysis, age showed a significant negative correlation with BMD expressed as $\mathrm{g} / \mathrm{cm}^{2}$ in femoral neck and lumbar spine both in patient and control groups (Pearson's coefficient, $r=-0.4$, $P<0.01$ in both cases). A significant positive correlation was also found between age and BMI $(r=0.3$, $P<0.01)$, and PTH levels correlated weakly with age $(r=0.3, P<0.05)$ but not with other bone turnover markers or with $1-25(\mathrm{OH}) 2$ vit $\mathrm{D}$ or $25(\mathrm{OH})$ vit $\mathrm{D}$. No correlation was found between menopause duration and BMD.

\section{Discussion}

The results reported in our study do not demonstrate a deleterious effect of long-term suppressive LT4 treatment on bone integrity in women with differentiated thyroid carcinoma, regardless of their estrogen status. The potential changes in BMD in endogenous or induced subclinical hyperthyroidism remains a controversial issue and previous articles have failed to demonstrate uniform results (McDermott et al. 1995, Toft 2001, Quan et al. 2002, Murphy \& Williams 2004). Owing to the observed $80-90 \%$ disease-free survival in differentiated thyroid carcinoma patients at 10 years of follow-up (Gullberg et al. 1997) and the recommendations for full suppression of TSH to $<0.1 \mu \mathrm{IU} / \mathrm{ml}$ (Harris 2002), the potentially deleterious effect of LT4 treatment in BMD is a matter of concern. In fact, the Clinical Practice Recommendations for the Management of Thyroid Carcinoma suggest a risk of accelerated bone turnover but do not express definitive recommendations for its monitoring (Thyroid Carcinoma Task Force 2001). Previous studies have been focused both on endogenous and drug-induced subclinical hyperthyroidism (Franklyn et al. 1992, Kung et al. 1993, Giannini et al. 1994, Marcocci 

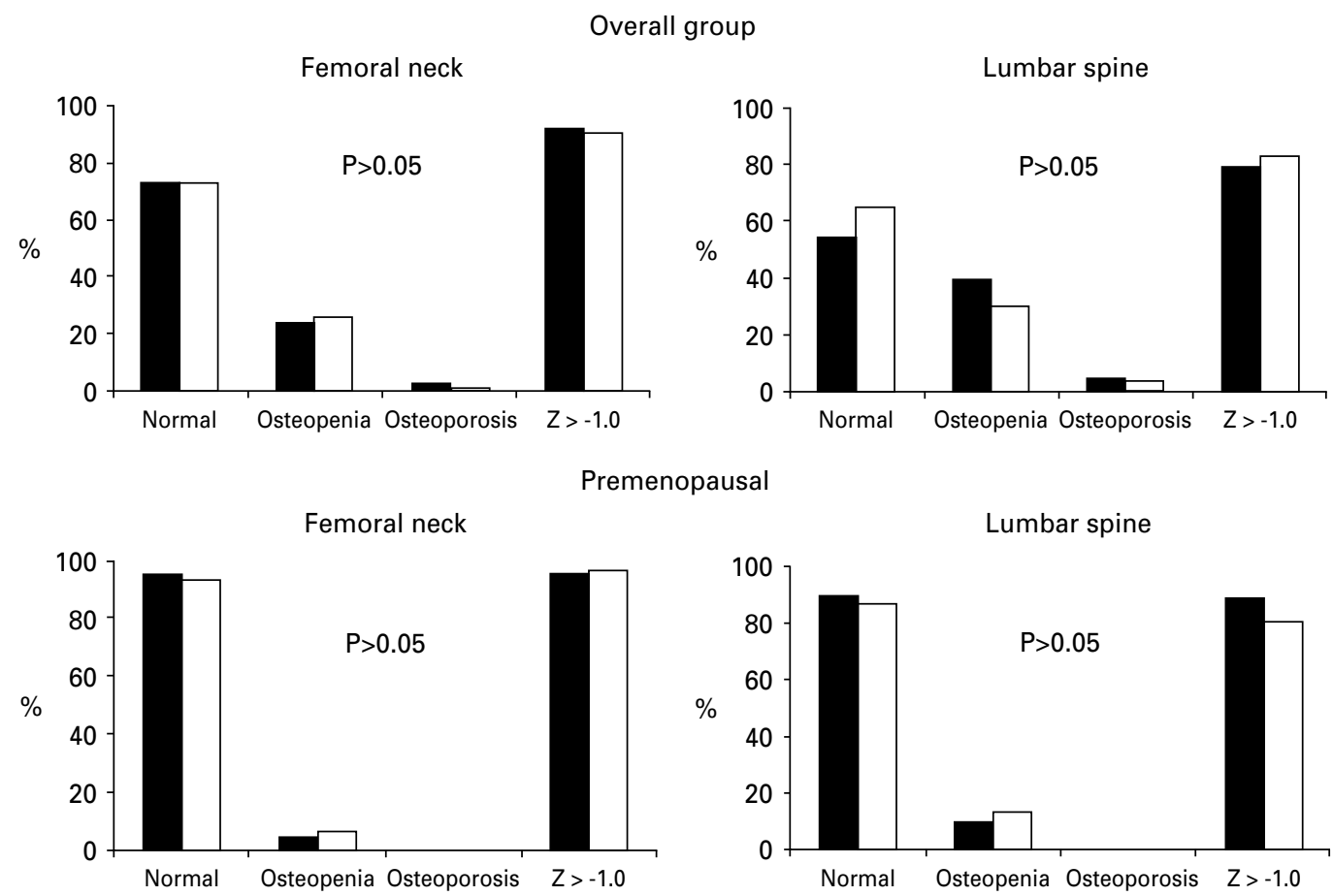

\section{nopausal}

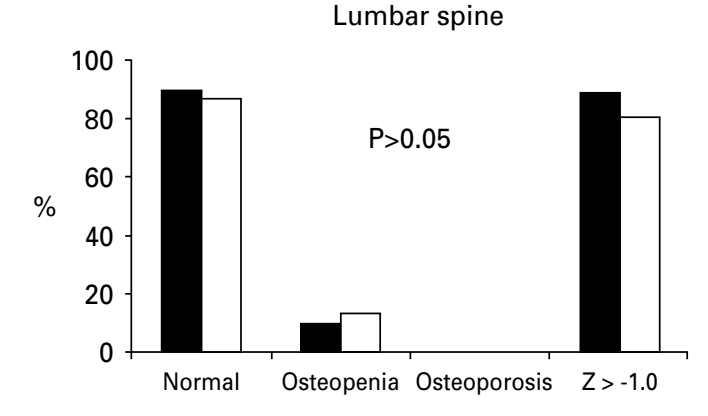

Postmenopausal
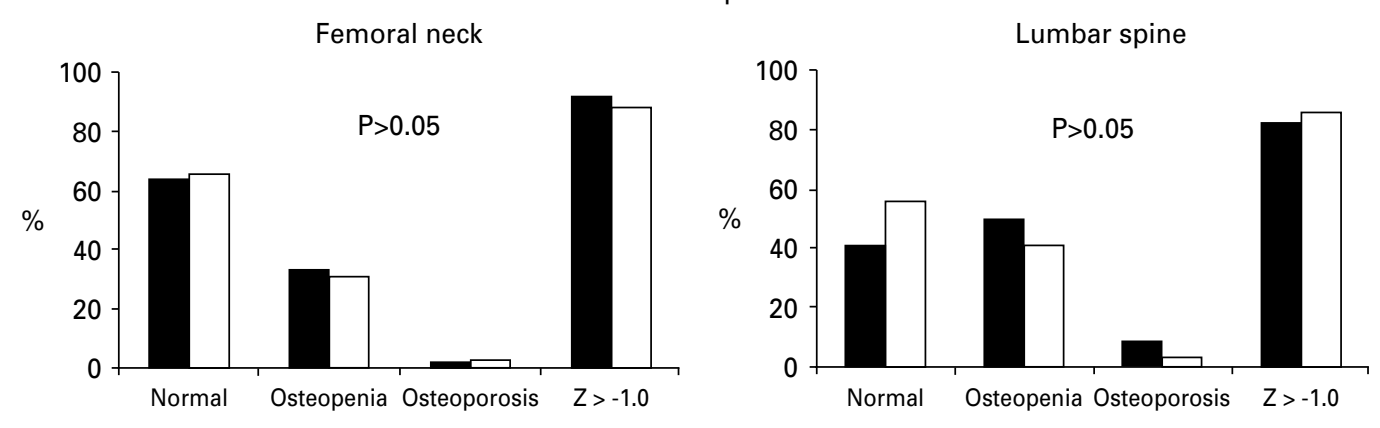

Figure 1 Comparison between patients and controls of bone mineral density expressed as normal, osteopenia and osteoporosis (according to T-score) and normal Z-score $(Z>-1.0)$ in femoral neck (left panels) and lumbar spine (right panels) in the overall group $(n=88)$, in premenopausal $(n=44)$ and in postmenopausal women $(n=44)$. Bars represent percentage of subjects in each group (black bars, controls; white bars, patients).

et al. 1994, McDermott et al. 1995, Muller et al. 1995, Rosen et al. 1998). In two studies, patients with nodular goitre and endogenous subclinical hyperthyroidism had lower BMD than comparable normal subjects (Mudde et al. 1992, Foldes et al. 1993), although in one trial significant reductions in BMD occurred only in postmenopausal and in sites rich in cortical bone (Foldes et al. 1993). Some authors described decreased BMD in pre- and postmenopausal women with a significant negative correlation with T3 levels (Tauchmanovà et al. 2004). In other reports only postmenopausal women were affected (Faber \& Galloe
1994) or no diminution was observed (Franklyn et al. 1992, Giannini et al. 1994, Marcocci et al. 1994, Muller et al. 1995, Rosen et al. 1998). With respect to hyperthyroidism due to suppressive LT4 treatment, some trials included premenopausal women with little or no change in BMD between controls and long-term treated patients (Franklyn et al. 1992, Giannini et al. 1994, Marcocci et al. 1994, Muller et al. 1995). Studies performed in postmenopausal women showed decreased BMD in all measured sites in two trials (Diamon et al. 1991, Kung \& Yeung 1996) and no changes in another six (Franklyn et al. 1992, Giannini 
Table 1. Characteristics of premenopausal and postmenopausal patients treated with levothyroxine for differentiated thyroid carcinoma compared with healthy controls. Data are means $\pm S D$. No significant differences were detected between patients and controls

\begin{tabular}{|c|c|c|c|c|}
\hline & \multicolumn{2}{|c|}{ Premenopausal } & \multicolumn{2}{|c|}{ Menopausal } \\
\hline & Patients $(n=44)$ & Controls $(n=44)$ & Patients $(n=44)$ & Controls $(n=44)$ \\
\hline Age (years) & $39 \pm 9$ & $41 \pm 11$ & $58 \pm 9$ & $57 \pm 2$ \\
\hline Body mass index $\left(\mathrm{Kg} / \mathrm{m}^{2}\right)$ & $26.1 \pm 5$ & $25.5 \pm 4.1$ & $28.0 \pm 2.6$ & $27.2 \pm 3.6$ \\
\hline Menarche (years) & $12.1 \pm 1.3$ & $12.6 \pm 1.3$ & $12.7 \pm 1.3$ & $12.3 \pm 1.4$ \\
\hline Menopause (years) & - & - & $46 \pm 4$ & $47 \pm 5$ \\
\hline Menopause duration (years) & - & - & $10 \pm 3$ & $10 \pm 3$ \\
\hline \multicolumn{5}{|l|}{ Previous contraceptives } \\
\hline Subjects $(n)$ & 12 & 12 & 12 & 11 \\
\hline years & $3.2 \pm 1.7$ & $4.4 \pm 2.6$ & $4.0 \pm 2.2$ & $4.5 \pm 1.5$ \\
\hline \multicolumn{5}{|l|}{ Coffee intake $(n)$} \\
\hline $0-2$ units $/ 24 \mathrm{~h}$ & 36 & 37 & 36 & 37 \\
\hline 3-4 units/24 h & 8 & 7 & 8 & 7 \\
\hline Smokers $(n)$ & 14 & 13 & 5 & 5 \\
\hline \multicolumn{5}{|l|}{ Alcohol intake $(n)$} \\
\hline 0 units $/ 24 \mathrm{~h}$ & 38 & 37 & 39 & 40 \\
\hline $1-2$ units/24 h & 6 & 7 & 5 & 4 \\
\hline \multicolumn{5}{|l|}{ Exercise $(n)$} \\
\hline Mild & 3 & 4 & 4 & 3 \\
\hline Moderate & 39 & 38 & 38 & 39 \\
\hline Vigorous & 2 & 2 & 2 & 2 \\
\hline
\end{tabular}

Table 2. Hormonal, calcium metabolism and bone turnover parameters of premenopausal and postmenopausal patients treated with thyroxine for differentiated thyroid carcinoma and healthy controls. Date are means $\pm S D$

\begin{tabular}{|c|c|c|c|c|}
\hline & \multicolumn{2}{|c|}{ Premenopausal } & \multicolumn{2}{|c|}{ Postmenopausal } \\
\hline & $\begin{array}{c}\text { Patients } \\
(n=44)\end{array}$ & $\begin{array}{c}\text { Controls } \\
(n=44)\end{array}$ & $\begin{array}{c}\text { Patients } \\
(n=44)\end{array}$ & $\begin{array}{c}\text { Controls } \\
(n=44)\end{array}$ \\
\hline TSH $(\mu \mathrm{IU} / \mathrm{mL})$ & $0.02 \pm 0.01$ & $2.1 \pm 0.9^{*}$ & $0.04 \pm 0.03$ & $1.8 \pm 1.0^{\star}$ \\
\hline FreeT4 (ng/dL) & $2.0 \pm 0.3$ & $1.3 \pm 0.2^{*}$ & $1.9 \pm 0.4$ & $1.2 \pm 0.1^{*}$ \\
\hline Total T3 (ng/mL) & $1.2 \pm 0.3$ & $1.3 \pm 0.2$ & $1.3 \pm 0.3$ & $1.3 \pm 0.3$ \\
\hline Calcium (mg/dL) & $9.1 \pm 0.4$ & $9.3 \pm 0.4$ & $9.4 \pm 0.5$ & $9.4 \pm 0.4$ \\
\hline Phosphate (mg/dL) & $3.5 \pm 0.5$ & $3.4 \pm 0.7$ & $3.5 \pm 0.7$ & $3.3 \pm 0.8$ \\
\hline PTH $(\mathrm{pg} / \mathrm{mL})$ & $33.9 \pm 13.9$ & $45.1 \pm 17.2^{*}$ & $43.6 \pm 20.6$ & $50.7 \pm 17.6^{\#}$ \\
\hline $1-25(\mathrm{OH})_{2}$ vitD $(\mathrm{pg} / \mathrm{mL})$ & $36.0 \pm 20.0$ & $30.0 \pm 10.0$ & $34.7 \pm 17.4$ & $35.8 \pm 24.3$ \\
\hline $25(\mathrm{OH}) \mathrm{vitD}(\mathrm{ng} / \mathrm{mL})$ & $43.0 \pm 37.7$ & $37.3 \pm 17.2$ & $33.9 \pm 14.9$ & $38.5 \pm 20.4$ \\
\hline Urinary calcium (mg/24 h) & $180.6 \pm 68.0$ & $143.5 \pm 55.0$ & $165.0 \pm 102.9$ & $152.1 \pm 83.4$ \\
\hline N-Telopeptide (nMBCE/mMcr) & $34.7 \pm 11.1$ & $29.6 \pm 9.9$ & $46.4 \pm 26.9$ & $44.2 \pm 24.2$ \\
\hline
\end{tabular}

${ }^{\star} P<0.01$ compared with controls.

${ }^{\#} P<0.05$ compared with controls.

et al. 1994, Hawkins et al. 1994, Marcocci et al. 1994, Muller et al. 1995, Görres et al. 1996, Guo et al. 1997). Factors such as case-control matching, dietary calcium intake, alcohol, smoking, exercise and bone mass measurement techniques, could explain in part this conflicting evidence (Greenspan \& Greenspan 1999, Murphy \& Williams 2004). In our study, subjects and methods were carefully selected in order to minimize these confounding factors. First, only women were included, since osteoporosis is an important cause of morbidity in women and the great proportion of female patients in our series of thyroid carcinoma was high (near $85 \%$ ). Second, we selected only cases with stable TSH levels, below $0.05 \mu \mathrm{IU} / \mathrm{ml}$ in all the determinations performed during follow-up previous to entry in the study. Third, TT3 levels were within normal range in all patients in all the previous follow-up determinations, thus ruling out possible 
overt hyperthyroidism with a known effect on bone turnover. Fourth, treatment in our series is long-term, lasting more than 30 years in some cases. Fifth, the measurement technique was a modern DEXA evaluation with higher precision and reproducibility than other older techniques (Baran et al. 1997), and sixth, in our series, careful matching for age, BMI, menopausal status, unhealthy habits, calcium intake and physical activity was made with a healthy control group. In agreement with a previous long-term treatment study in which all patients achieved complete TSH suppression and pre- and postmenopausal patients were evaluated with DEXA (Giannini et al. 1994), our results suggest that suppressive LT4 treatment does not affect bone mineralization or bone turnover parameters. It is of particular interest that in the postmenopausal group, more patients than controls had normal T-scores, i.e. our treated patients could have good bone mineralization despite receiving LT4 for many years. In successive reviews on suppressive treatment for thyroid carcinoma, the conclusions and recommendations seem unclear and have changed over time and with authors. In 1999, Greenspan \& Greenspan suggested that exogenous hyperthyroidism seemed to have an adverse effect on bone, which was greater in postmenopausal women (Greenspan \& Greenspan 1999). Two years later, Toft reported that the evidence of exogenous subclinical hyperthyroidism as a risk factor for osteoporosis was inconclusive (Toft 2001). Finally, the 2004 Guidelines for diagnosis and management of subclinical thyroid disease (Surks et al. 2004) and Murphy \& William's review (Murphy \& Williams 2004) suggested that suppressive doses of LT4 had little or no effect on the BMD of premenopausal women or men. The situation in postmenopausal women remained less clear and it is recommended that all other risk factors for osteoporosis be considered in these patients (Murphy \& Williams 2004). In our series, we detected consistently elevated levels of PTH in controls compared with patients. This increase was not due to an undetected subclinical hypoparathyroidism in patients because in all cases PTH was within normal range and maintained the physiological positive correlation with age, as observed in controls. We do not have an explanation for this observation. The effect of radioiodine on parathyroid glands could produce a diminution in their secretion capacity (Cooper 2005) and hypoparathyroidism has been reported after radioiodine therapy, however this probably does not exceed the normal incidence (Pauwels et al. 2000). On the other hand, an effect of chance cannot be ruled out for this finding. In differentiated thyroid carcinoma, the dose of LT4 usually required to maintain full suppression of TSH to levels less than $0.01 \mu \mathrm{IU} / \mathrm{ml}$ is approximately $2.2 \mu \mathrm{g} /$ $\mathrm{kg}$ (Burmeister et al. 1992) and some studies suggest that higher doses are associated with greater bone loss (Mikosch et al. 2003). In our treated group, median LT4 dose was $2.7 \mu \mathrm{g} / \mathrm{kg}$, without bone loss. The normality of TT3 levels in all cases could explain this lack of effect. According to our data, long-term treatment with supraphysiological doses of LT4 in patients with differentiated thyroid carcinoma and complete suppression of TSH, even for a period of more than 30 years, does not appear to contribute to bone demineralization. However, individual management is required in these patients and other risk factors for osteoporosis and DEXA evaluation should be considered in postmenopausal women. It is of interest that, as detected in our study population, nearly $50 \%$ of women did not achieve the recommended daily calcium intake. Thus, recommendations focused on daily physical activity, increased calcium intake and, specifically in countries with low sunlight exposure, adequate vitamin D supplementation, could be of interest to prevent the physiological loss of bone mass with age.

\section{Acknowledgement}

The authors thank Christine O'Hara for valuable help with the English version of the manuscript. Part of this work has been accepted for poster presentation at 7 th European Congress of Endocrinology, Göteborg, Sweden, 3-7 September 2005.

\section{Funding}

The authors declare no conflict of interest that would prejudice the impartiality of this study and no financial disclosure.

\section{References}

Baran DT, Faulkner KG, Genant HK, Miller PD \& Pacifici R 1997 Diagnosis and management of osteoporosis: guidelines for the utilization of bone densitometry. Calcified Tissue International 61 433-440.

Burmeister LA, Goumaz MO, Mariash CN \& Oppenheimer JH 1992 Levothyroxine dose requirements for thyrotropin suppression in the treatment of differentiated thyroid cancer. Journal of Clinical Endocrinology and Metabolism 75 344-350.

Cooper C, Campion G \& Melton LJ III 1992 Hip fractures in the elderly: a worldwide projection. Osteoporosis International 2 285-289. 
Cooper S 2005. Treatment of thyrotoxicosis. In Werner \& Ingbar's The thyroid. A fundamental and clinical text, 9 edn, pp 665-694. Eds LE Braverman \& RD Utiger. Philadelphia: Lippincott Williams \& Wilkins.

Diamon T, Nery L \& Hales I 1991 A therapeutic dilemma: suppressive doses of thyroxine significantly reduce bone mineral measurements in both premenopausal and postmenopausal women with thyroid carcinoma. Journal of Clinical Endocrinology and Metabolism 72 1184-1188.

Faber J \& Galloe AM 1994 Changes in bone mass during prolonged subclinical hyperthyroidism due to L-thyroxine treatment: a meta-analysis. European Journal of Endocrinology 130 350-356.

Foldes J, Tarjan G, Szathmari M, Varga F, Krasznai I \& Horvath C 1993 Bone mineral density in patients with endogenous subclinical thyrotoxicosis: is this thyroid status a risk factor for osteoporosis? Clinical Endocrinology 39 521-527.

Franklyn JA, Betteridge J, Daykin J, Holder R, Oates GD, Parle JV, Lilley J, Heath DA \& Sheppard MC 1992 Long-term thyroxine treatment and bone mineral density. Lancet 340 9-13.

Giannini S, Nobile M, Sartori L, Binotto P, Ciuffreda M, Gemo G, Pelizzo MR, D’Angelo A \& Crepaldi G 1994 Bone density and mineral metabolism in thyroidectomized patients treated with long term L-thyroxine. Clinical Science 87 593-597.

Gilliland FD, Hunt WC, Morris DM \& Key CR 1997 Prognostic factors for thyroid carcinoma. A populationbased study of 15,698 cases from the Surveillance, Epidemiology and End Results (SEER) program 1973-1991. Cancer 9 564-573.

Görres G, Kaim A, Otte A, Götze M \& Muller-Brand J 1996 Bone mineral density in patients receiving suppressive doses of thyroxine for differentiated thyroid carcinoma. European Journal of Nuclear Medicine $\mathbf{2 3}$ 690-692.

Greenspan SL \& Greenspan FS 1999 The effect of thyroid hormone on skeletal integrity. Annals of Internal Medicine 130 750-758.

Gullberg B, Johnell O \& Kanis JA 1997 World-wide projections for hip fracture. Osteoporosis International 7 407-413.

Guo CY, Weetman AP \& Eastell R 1997 Longitudinal changes in bone mineral density and bone turnover in postmenopausal women on thyroxine. Clinical Endocrinology 46 301-307.

Harris PE 2002 The management of thyroid cancer in adults: a review of new guidelines. Clinical Medicine 2 144-146.

Hawkins F, Rigopoulou D, Papapietro K \& Lopez MB 1994 Spinal bone mass after long-term treatment with L-thyroxine in postmenopausal women with thyroid cancer and chronic lymphocytic thyroiditis. Calcified Tissue International 54 16-19.

Jemal A, Murray T, Samuels A, Ghafoor A, Ward E \& Thun MJ 2003 Cancer Statistics. CA: a Cancer Journal for Clinicians 53 5-26.
Kanis JA, Melton LJ III, Christiansen C, Johnston CC \& Khaltaev N 1994 The diagnosis of osteoporosis. Journal of Bone and Mineral Research 9 1137-1141.

Kung AW \& Yeung SS 1996 Prevention of bone loss induced by thyroxine suppresive therapy in postmenopausal women: the effect of calcium and calcitonin. Journal of Clinical Endocrinology and Metabolism 81 1232-1236.

Kung AW, Lorentz T \& Tam SC 1993 Thyroxine suppressive therapy decreases bone mineral density in postmenopausal women. Clinical Endocrinology 39 535-540.

Lau EM, Suriwongpaisal P, Lee JK, Das De S, Festin MR, Saw SM, Khir A, Torralba T, Sham A \& Sambrook P 2001 Risk factors for hip fracture in Asian men and women: the Asian osteoporosis study. Journal of Bone and Mineral Research 16 572-580.

Marcocci C, Golia F, Bruno-Bossio G, Vignali E \& Pinchera A 1994 Carefully monitored levothyroxine suppressive therapy is not associated with bone loss in premenopausal women. Journal of Clinical Endocrinology and Metabolism 78 818-823.

McDermott MT, Perloff JJ \& Kidd GS 1995 A longitudinal assessment of bone loss in women with levothyroxinesuppressed benign thyroid disease and thyroid cancer. Calcified Tissue International 56 521-525.

Mikosch P, Obermayer-Pietsch B, Jost R, Jauk B, Gallowitsch HJ, Kresnik E, Leb G \& Lind P 2003 Bone metabolism in patients with differentiated thyroid carcinoma receiving suppressive levothyroxine treatment. Thyroid 13 347-335.

Mudde AH, Reijnders FJL \& Kruseman AC 1992 Peripheral bone density in women with untreated multinodular goitre. Clinical Endocrinology 37 35-39.

Muller CG, Bayley TA, Harrison JE \& Tsang R 1995 Possible limited bone loss with suppressive thyroxine therapy is unlikely to have clinical relevance. Thyroid $\mathbf{5}$ 81-87.

Murphy E \& Williams GR 2004 The thyroid and the skeleton. Clinical Endocrinology 61 285-298.

Pauwels EK, Smit JW, Slats A, Bourguignon M \& Overbeek F 2000 Health effects of therapeutic use of 131I in hyperthyroidism. Quarterly Journal of Nuclear Medicine and Molecular Imaging 44 333-339.

Quan ML, Pasieka JL \& Rorstad O 2002 Bone mineral density in well-differentiated thyroid cancer patients treated with suppressive thyroxine: a systematic overview of the literature. Journal of Surgical Oncology $7972-79$.

Rosen HN, Moses AC, Garber J, Ross DS, Lee SL, Ferguson L, Chen V, Lee K \& Greenspan S 1998 Randomized trial of pamidronate in patients with thyroid cancer: bone density is not reduced by suppressive doses of thyroxine, but is increased by cyclic intravenous pamidronate. Journal of Clinical Endocrinology and Metabolism $\mathbf{8 3}$ 2324-2330.

Ross DS 1994 Hyperthyroidism, thyroid hormone, and bone. Thyroid 4 319-326. 
Surks MI, Ortiz E \& Daniels GH 2004 Subclinical thryoid disease: scientific review and guidelines for diagnosis and management. Journal of the American Medical Association 291 228-238.

Tauchmanovà L, Nuzzo V \& Del Puente A 2004 Reduced bone mass detected by bone quantitative ultrasonometry and DEXA in pre- and postmenopausal women with endogenous subclinical hyperthyroidism. Maturitas 48 299-306.

Thyroid Carcinoma Task Force 2001 AACE/AAES Medical/Surgical guidelines for clinical practice: management of thyroid carcinoma. American Association of Clinical Endocrinologists. American
College of Endocrinology. Endocrine Practice 7 202-220.

Toft A 2001 Subclinical hyperthyroidism. New England Journal of Medicine 345 512-516.

Uzzan B, Campos J, Cucherat M, Nony P, Boissel JP \& Perret GY 1996 Effects on bone mass of long term treatment with thyroid hormones: a meta-analysis. Journal of Clinical Endocrinology and Metabolism 81 4278-4289.

Von Recklinhausen F 1891 Die fibrose oder deformiedere ostitis, die osteomalazie und die osteoplastische karzinose in ihren gegenseitigen beziehungen. In: Festschrift Rudolf Virchow. Berlin. George Reimer 1. 
